\title{
Guerra del Pacífico y construcción de la justicia: los procesos penales en Lima durante la ocupación chilena
}

\author{
José Chaupis Torres ${ }^{1}$ \\ Recibido: 10 de septiembre de 2015 - Aceptado: 20 de octubre de 2015
}

\begin{abstract}
Resumen
En los últimos años se han visto incrementados, de manera bastante significativa, los estudios en torno a la Guerra del Pacífico. A pesar de ello la coyuntura de la ocupación de Lima por Chile es un tema que falta investigar, en especial el vinculado a los aspectos de carácter jurídico institucional y la práctica judicial. En una primera parte se buscará indagar sobre el proyecto político de justicia criminal de Chile en Perú, como un Estado que terminó desdoblándose debido a las dificultades que implicaba la administración de una ciudad capital ocupada como Lima. En una segunda parte se estudiará el impacto de estas normativas jurídicas y cómo fueron interpretadas por los diferentes actores sociales, a partir de un estudio deconstructivo de los expedientes judiciales, para comprender la imagen de justicia que emerge desde el mismo sujeto histórico y cómo fueron desarrollando su agencia histórica, en una coyuntura de inevitable convivencia.
\end{abstract}

Palabras clave: Ocupación de Lima, Guerra del Pacífico, justicia criminal, práctica judicial, sistema dual.

\section{War of the Pacific and construction of justice: criminal proceedings in lima during chilean occupation}

\begin{abstract}
In recent years, studies around the War of the Pacific have significantly increased. However, the situation of the Chilean occupation of Lima is an issue of research, especially linked to the institutional aspects of legal and judicial practice. The first part will seek to investigate the political project of criminal justice by Chile in Peru, as a State that ended unfolding due to the difficulties involved in the administration of an occupied capital city as Lima. The second part will study the impact of these legal regulations and how different social actors, from a deconstructive study of court records, interpreted them in order
\end{abstract}


to understand the image of justice that emerges from the same historical subject and how they were developing a historical agency, in a context of unavoidable coexistence.

Keywords: Lima occupation, Pacific War, criminal justice, judicial practice, dual system

\title{
Guerra do Pacífico e construção da justiça: os processos penais em Lima durante a ocupação chilena
}

\begin{abstract}
Resumo
Nos últimos anos, têm-se avistado o aumento, de forma bastante significativa, dos estudos em torno da Guerra do Pacífico. No entanto, a situação da ocupação de Lima pelo Chile é uma questão que continua a serem investigados, especialmente os relacionados com os aspectos de caráter jurídico institucional e da prática judicial. A primeira parte vai procurar investigar o projeto político da justiça penal de Chile no Peru, como um Estado que terminou se desdobrando devido às dificuldades que implica a administração de uma cidade capital ocupada como Lima. Na segunda parte, a pesquisa vai estudar o impacto destes regulamentos jurídicos e como foram interpretadas pelos diferentes atores sociais, a partir de um estudo deconstrutivo dos expedientes judiciais, para compreender a imagem de justiça que surge a partir do mesmo sujeito histórico e como foram desenvolvendo sua agência histórica, num contexto de convivência inevitável.
\end{abstract}

Palavras-chave: Ocupação de Lima, Guerra do Pacífico, justiça penal, prática judicial, sistema dual.

En los últimos años se han visto incrementados, de manera bastante significativa, los estudios en torno a la Guerra del Pacífico, siendo investigadas las más diversas temáticas (Chaupis Torres y Rosario, 2007). A pesar de ello, la coyuntura de la ocupación de Lima por Chile es un tema que aún falta investigar, en especial el vinculado a los aspectos de carácter jurídico institucional y la práctica judicial. La invasión de la capital por los chilenos supuso no solo la ocupación político-militar y económica de Lima, sino también una que podríamos llamar jurídico-social. Durante los años de ocupación (1881-1883) se estableció una especie de sociedad alterna a la peruana, siendo la convivencia uno de los problemas más difíciles que tuvo que afrontar el régimen de invasión chileno, lo cual se expresa en la conflictividad interna a través de la vida cotidiana llevada a los tribunales de justicia. La administración chilena buscó mantener el orden necesario al interior de estas sociedades paralelas, donde estaban incluidas también las diversas colonias extranjeras. Una forma de llevar a cabo esta política controlista en convivencia fue a través de la administración de justicia, más aún cuando el despacho judicial peruano se autoclausuró, siendo 
reemplazado por el sistema de justicia implementado por los chilenos. El establecimiento por parte de los ejércitos de ocupación de los juzgados de letras y del crimen en Lima fueron aceptados por los diferentes grupos sociales peruanos y extranjeros, debido a la necesidad de un sistema de solución de los conflictos. La presente investigación se estructurará en dos partes. En una primera parte se buscará indagar sobre el proyecto político de justicia criminal de Chile en Perú, como un Estado que terminó desdoblándose debido a las dificultades que implicaba la administración de una ciudad capital ocupada como Lima. La administración de justicia establecida por los invasores organizó un sistema dual, por el cual empleó pragmáticamente tanto la legislación chilena como peruana, para superar los conflictos interpersonales en su búsqueda por mantener el orden social, el cual terminó fracasando, aceptando finalmente la justicia chilena. En una segunda parte se estudiará el impacto de estas normativas jurídicas y cómo fueron interpretadas por los diferentes actores sociales, a partir de un estudio deconstructivo de los expedientes judiciales, para comprender la imagen de justicia que emerge desde el mismo sujeto histórico y cómo fueron desarrollando su capacidad de agencia frente a los tribunales, en una coyuntura de inevitable convivencia social. Se busca analizar la justicia como problema de Estado, vinculándolo con lo cotidiano a través de las prácticas de los litigantes. Estudiar el proceso de formación de la justicia y su administración a través de los agentes judiciales dentro de un contexto bélico de ocupación, nos permitirá ampliar las perspectivas para comprender en amplitud la Guerra del Pacífico.

\section{El proyecto político de justicia criminal de Chile durante la ocupación de Lima}

La ocupación de Lima iniciada en 1881 se convertiría en un acontecimiento clave en el desarrollo posterior de la guerra contra Chile, que venía sosteniéndose desde 1879; no sólo porque evidenciaba la superioridad bélica del invasor, sino porque dicha situación, rescenificaba por segunda vez -desde iniciado el conflicto externo- todo la estructura del poder político del Estado peruano. Nicolás de Piérola quien había acabado con el régimen pradista a fines de 1879, se encontraba para inicios de 1881 dirigiéndose a la sierra central, con el objetivo de organizar la resistencia para continuar con la defensa del país. Su partida hacia el interior del Perú llevaría a su desconocimiento como primer mandatario, por parte principalmente de los grupos civilistas y el alto mando militar chileno (Rivera, 1984: 25). Los primeros, adversarios políticos declarados del pierolismo; los segundos, conocedores del rechazo por parte de Piérola de firmar la paz con cesión territorial. 
Para los peruanos, volver a constituir un nuevo poder político alternativo al de Piérola, en las condiciones en que se estaba, era sumamente difícil. Tuvo que llevarse a cabo un esfuerzo conjunto entre parte de las elites peruanas y las fuerzas chilenas de ocupación (Rosario, 2014: 218), para intentar constituir en la medida de lo posible un gobierno representativo legitimado por la población, que tuviese la capacidad de desplazar al Califa del escenario político peruano. En tanto los chilenos habrían de evaluar que su estadía en Lima no debería ser prolongada, alargar su permanencia le ocasionaría altos costos a su tesoro público, por tanto debían buscar lo más pronto, la rendición incondicional de los peruanos para poder así obtener la tan anhelada paz con cesión territorial que incluyera las riquezas salitreras (Abanto, 2012: 45).

El problema era el faccionalismo imperante debido al colapso del régimen pierolista; ante ello Chile actuó como un poder más en la lucha por el dominio del Perú (McEvoy, 2011: 345), que para establecer su autoridad debía controlar la estructura del Estado, siendo una de las instituciones el Poder Judicial, que permitiría imponer el orden y superar los conflictos producidos por la convivencia entre chilenos y peruanos y las colonias extranjeras. El tema de la forma en "que se resolvió la administración de justicia, mecanismos de composición de conflictos y represión de conductas antijurídicas" (Aguilar, 2012: 83), así como la convivencia entre estas poblaciones durante la ocupación militar de la ciudad capital, han sido poco investigados por la historiografía peruana. Sobre el primero, el poco interés se debe a que "no se logró ningún aporte positivo ni desarrollo jurisprudencial así como tampoco vieron la luz sesudos análisis o grandes codificaciones. Eso hace que este periodo pase, a los ojos del historiador, como un periodo yermo en lo que al derecho peruano se refiere" (Aguilar, 2012: 85). Con respecto al segundo ha predominado una tendencia nacionalista que sostiene el rechazo de la población limeña a los ejércitos chilenos. Historiadores como Raúl Rivera Serna (1984), Jorge Basadre (2005) y Margarita Guerra (1991), entre otros:

"Usaron principalmente como fuentes históricas los testimonios de ciudadanos extranjeros y de ocupantes chilenos durante los primeros días de la ocupación. Dichos testimonios muestran una evidente reacción hostil de la población limeña ante la situación de vulnerabilidad generada por la reciente derrota peruana ante el ejército chileno. No obstante la ocupación duró casi tres años. ¿Cómo interactuaron la población peruana y el ejército chileno durante ese tiempo?" (Valle Vera, 2013: 7).

Para el desarrollo del presente trabajo se utilizarán los expedientes judiciales criminales tramitados durante el periodo de la ocupación, los cuales llegan a 411 expedientes en el Archivo General de la Nación de Lima. Como 
señala Marcos Fernández Labbé (2000: 110-111), el objetivo de las fuentes judiciales es:

"relatar procesos mediante los cuales se consigue la reconstitución efectiva de hechos que, por su naturaleza transgresora, han convocado la presencia de las justicias en un determinado tiempo y lugar, con el objeto de que estos mismos hechos sean evaluados y categorizados, objetivados en relación a un marco de interpretación definido por el Código, y de acuerdo a ello, sean conducentes a la aplicación de un castigo predefinido como proporcional a la gravedad de los hechos cometidos".

Con relación a la legislación criminal vigente en Perú y Chile durante los años de la ocupación de Lima se encuentran dos documentos jurídicos. El primero fue el código penal peruano de 1863 que tiene características similares a la mayoría de los países hispanoamericanos, como el código penal chileno de 1874, en la medida que un código redactado en un país servía como referencia para otros, produciéndose mutuas influencias en sus leyes penales (Iñesta Pastor, 2005: 1073). Con respecto a la orientación doctrinal de estos códigos podríamos ubicarlos al interior de la llamada Escuela Clásica, encontrándose inspirados en el eclecticismo de Pellegrino Rossi, quien "aplicó el eclecticismo filosófico de Cousin al Derecho penal mediante un sistema ecléctico en el que la justicia prevalecía sobre la utilidad, fundamentando el derecho de penar en el orden moral" (Iñesta Pastor, 2008: 220). El pensamiento de Rossi fue a su vez retomado por Francisco Pacheco quien influenciaría en la elaboración del código penal español de 1848, el cual sería adoptado por los códigos hispanoamericanos debido a "que su contenido proviene casi íntegramente del derecho castellano que regía en España y América española. Por eso no hubo ningún obstáculo para reemplazar ese derecho castellano no codificado vigente hasta entonces, por el derecho castellano codificado de los nuevos textos legales" (Iñesta Pastor, 2008: 206). A partir de lo señalado para el código chileno de 1874 por Manuel de Rivacoba y Rivacoba (Iñesta Pastor, 2008: 220-221), podemos mencionar las siguientes características con relación a su política criminal: el humanitarismo en ambos códigos es relativo, con penas punitivas excesivamente crueles; el racionalismo se mezcla con el liberalismo a través de la legalidad del delito y la pena, el retribucionismo se observa en las diferentes penas, lo utilitario y preventivo se destaca en la publicidad, el individualismo y la igualdad para establecer la sentencia. Tanto en Perú como en Chile los códigos fueron bien recibidos por sus contemporáneos:

"El Código peruano de 1863 fue valorado muy positivamente. El penalista Víctor M. Maúrtua lo califica de serio, elevado y de técnica perfecta. Smithe lo considera ampliamente satisfactorio. Moderna- 
mente Peña Cabrera destaca en él su claridad y valía técnica. Tuvo larga vigencia ya que se mantuvo hasta 1924, a pesar de diversos intentos realizados para su reforma" (Iñesta Pastor, 2005: 1084).

A pesar de ello también hubo fuertes críticas en ambos países. En Chile el destacado penalista Rafael Fontecilla menciona que "largo sería enumerar los defectos científicos y técnicos que contiene" (Iñesta Pastor, 2008: 242). En Perú, Altmann Smythe señalaba que tenía "numerosos vacíos y errores" y Jorge Basadre Ayulo resaltaba que "tuvo muchos defectos en la forma y ambigüedad en la redacción de algunos artículos" (Aguilar, 2012: 51).

El segundo documento son las constituciones políticas de ambos países que tuvieron vigencia normativa durante la ocupación de Lima. En el caso peruano, fue la constitución de 1860, la cual no sería estrictamente liberal ni conservadora, sino moderada o centrista, incluso podría catalogarse de conciliadora. Con relación a su política criminal en el plano legislativo constitucional puede observarse una carencia normativa que de forma expresa la regule, caracterizándose por ser difusa, imprecisa, exigua, reflejando poca claridad en la reacción penal (Garaycott, 2012: 27-35). La constitución chilena vigente en los años de la ocupación de Lima fue la de 1833, que se caracterizó por su conservadurismo, dándole forma jurídica a un proceso centralizador y autoritario que buscaba imponer un orden (Zúñiga Urbina, 2010: 381). La política criminal aunque buscaba establecer un nuevo orden constitucional, convirtiéndose en una verdadera norma jurídica, sus ideas terminaron siendo ambiguas y escuetas con relación al fenómeno delictivo.

El tercer documento legal sería el Estatuto Provisorio promulgado por Nicolás de Piérola en 1879,2 el cual a pesar de que sus doce artículos hacían gala de un "exceso retórico y proyectista" (Basadre, 2005, t. IX: 104), el objetivo fue darle un orden institucional más compacto al nuevo Estado surgido del golpe contra Mariano I. Prado a finales de 1879. Igual que la constitución de 1860 tuvo poca claridad, siendo por su brevedad bastante vaga, aunque "en teoría iba a cumplir una labor de "ley de guerra" que permitiese al Jefe Supremo tomar las decisiones más acertadas para afrontar el conflicto armado, terminó siendo en la realidad la primera piedra de una pretendida revolución normativa iniciada por Nicolás de Piérola" (Aguilar, 2012: 31). El artículo $5^{\circ}$ es el único que hace mención explícitamente del Poder Judicial, declarando el respeto a su independencia, aunque se reservaba el derecho

2 A lo largo del siglo XIX el Perú había tenido varios estatutos provisorios, los cuales a pesar de su diversidad tuvieron como objetivo organizar la estructura política del gobierno emergente, salido o no de un golpe de Estado, pudiendo, debido a las circunstancias de emergencia de los cuales surgían, reemplazar o no a la constitución; su principal característica fue la de tener un carácter transitorio. 
de fiscalizar la conducta de los órganos judiciales. ${ }^{3}$ El artículo $6^{\circ}$ dispone la vigencia de los códigos civil y penal, aunque supeditados a las reformas que vaya realizando el régimen pierolista en su intento por reformar el sistema judicial. ${ }^{4}$ El artículo $8^{\circ}$ amplía los casos en la aplicación de la pena de muerte -la cual había sido restablecida en la constitución de 1860-, mezclándose indistintamente los delitos de carácter político, económico, social, militar, los mismos que serían juzgados únicamente por el fuero castrense, aunque sobre este punto el Supremo Gobierno también se reservaba la facultad de confirmar, revocar o modificar en última instancia, y como tribunal de apelación, las sentencias pronunciadas por los consejos de guerra (Ahumada Moreno, 1886, t. III: 403). Todo esto "da una imagen clara del difícil panorama que, en plena guerra y en medio de un gobierno dictatorial, se presentaba para los magistrados y jueces" (Aguilar, 2012: 30).

A diferencia de los códigos penales que por su naturaleza se encontraban mejor estructurados, las constituciones políticas de ambos países y el Estatuto Provisorio de Piérola son muy imprecisas y ambiguas con respecto a su política criminal y la administración de justicia, a pesar de ello fueron la columna vertebral que organizó el marco legal cuando se produjo la invasión de la capital por los ejércitos chilenos. La derrota peruana en la campaña de Lima con la consiguiente ocupación de la capital deslegitimó el proyecto político utópico esperanzador de Nicolás de Piérola, en la medida que se sustentaba en los triunfos militares; las derrotas provocaron que la esperanza se fuera diluyendo y la desilusión se hiciera cada vez más extensiva entre la población (Chaupis Torres, 2012: 61-110). Cuando se produjo el ingreso de los ejércitos chilenos de ocupación el Poder Judicial se encontraba en su periodo vacacional, el cual se había iniciado el 24 de diciembre de 1880 y debía acabar el 14 de marzo de 1881, de acuerdo a lo dispuesto por el Califa en su decreto del 23 de marzo de 1880. ${ }^{5}$ Debido a ello Cornelio Saavedra, primer Jefe de la ocupación de Lima, le pide a Juan Antonio Ribeyro Presidente de la Corte Suprema, reasumir sus funciones para restablecer el normal servicio de justicia (Ramos Núñez, 2008: 235), frente a lo cual se negó acatando lo ordenado por Piérola. Lo mismo hizo con el Alcalde de Lima Rufino Torrico, obteniendo la misma negativa; ante esto intervino Manuel Baquedano, General en Jefe del Ejército chileno en Lima, quien en febrero de 1881 dispuso el establecimiento de la ley mar-

3 Por decreto del 16 de enero de 1880 dispuso el nombramiento de jueces y vocales buscando el control del Poder Judicial (Aguilar, 2012: 69).

4 El secretario de justicia e instrucción Federico Panizo anunciaba en una circular del 26 de diciembre de 1879 remitida a los tribunales de justicia del Perú con copia al Jefe Supremo la inmediata reforma del Poder Judicial (Atanasio Fuentes, 1881: 97).

5 Decreto del 23 de marzo de 1880. Disponible en http://www.congreso.gob.pe/ntley/lmagenes/LeyesXIX/1880039.pdf. 
cial, permitiéndole a las fuerzas de ocupación chilenas conocer las causas civiles y criminales, instaurándose el Tribunal Militar con lo cual dejaron de dialogar con el Poder Judicial (Aguilar, 2012: 98-103).

El fracaso de una paz inmediata obligó a la ocupación indefinida de Lima, promoviendo una representación nacional favorable a sus intereses. Impulsaron la instauración de un gobierno provisorio que asumiría además la administración de justicia. El recientemente elegido presidente García Calderón, nombró a José Miguel Vélez como Ministro de Justicia, Culto, Instrucción Pública y Beneficencia el 12 de marzo de 1881 a dos días de restablecerse el servicio judicial ante el fin del período vacacional. El 14 de marzo no se reiniciaron las actividades judiciales; ante ello se dispuso el restablecimiento de la Constitución de 1860, declarando por decreto del 29 de marzo la nulidad de todos los actos de gobierno establecidos por el gobierno jefatural:

"Art. $1^{\circ}$ El Poder Judicial de la República principiará sus funciones el día 18 de abril próximo y se sujetará en sus procedimientos a la Constitución política de 1860 y a las leyes vigentes en diciembre de 1879 .

Art. $2^{\circ}$ Los tribunales y juzgados se instalarán al principiar sus funciones con el personal que tenían en 21 de diciembre de 1879.

Art. $3^{\circ}$ Se declaran nulos y sin valor alguno los nombramientos de vocales, jueces y demás empleados del Poder Judicial hechos con posterioridad a la fecha citada.

Art. $4^{\circ}$ Los tribunales que no cumplan y hagan cumplir en sus distritos las prescripciones de este decreto en el momento de su instalación, incurrirán en las penas designadas en los artículos 125 y 126 del Código Penal.

El Ministro de Estado en el despacho de Justicia, Culto e Instrucción Pública y Beneficencia queda encargado del cumplimiento de este decreto" (Anales Judiciales, 1911, t. IV: 537).

Margarita Guerra (1991: 237) sostiene que esta actitud no era la más adecuada, se debía buscar la unidad y no incrementar los resentimientos. A pesar de esta compleja situación la autoridad suprema de la ocupación bajo el mando ahora de Patricio Lynch, no derogó el derecho peruano, por el contrario mantuvo su "vigencia temporal y espacial" a través de un sistema paralelo (Aguilar, 2012: 141-142). Este "derecho de la ocupación" como señala Gonzalo Aguilar se estructuró a través de un "Poder Judicial de la ocupación", asumiendo los casos civiles y criminales que antes estaban sujetos al Tribunal Militar en noviembre de 1881, en la medida que no satisfacía las necesidades de los diversos grupos sociales, al no tener un procedimiento estandarizado, con ausencia de una argumentación basada en el derecho 
que sustentase los fallos judiciales y la dependencia al General en Jefe de la ocupación (Aguilar, 2012: 200). Las causas civiles fueron vistas por el Juzgado de Letras y las causas criminales por el Juzgado del Crimen. En el primero se permitió la activa participación de los peruanos, mientras que en el segundo todos los agentes judiciales serían chilenos.

En la memoria del Ministerio de Justicia, Culto e instrucción Pública presentada ante el Congreso de Chile en 1881, se estableció que en materia criminal "en los territorios de Tarapacá, Tacna y Arica, imperaría la ley chilena, mientras que en los territorios de Lima y Callao la ley peruana" (De Ramón, 1989: 16). La fundamentación de este pragmático comportamiento jurídico fueron precedentes semejantes ocurridos en Europa durante el siglo XIX. En la memoria presentada ante el Congreso de 1882 se hace una reflexión sobre la necesidad de tratar debidamente a la población en los territorios ocupados, en la medida que la guerra pierde su sentido de barbarie cuando reconoce que la población del territorio ocupado no son enemigos; si se les considerase como tal habría el derecho de usar la violencia como recurso necesario; por el contrario, es la población la que sufre sus consecuencias, no tomando parte activa en la guerra:

"¿Por qué, pues, habría de tratarse como a enemigos a los que viven como gentes pacíficas? El solo hecho de ser ciudadano del Estado enemigo no justificaría esa medida; porque la guerra se hace hoy por un Estado contra otro Estado, y no contra los individuos pacíficos" (De Ramón, 1989: 17).

El imperativo de poner orden basado en el derecho con una retórica civilizadora, era parte de la forma como buscaban avanzar en una difícil guerra de posiciones, con diversos actores en conflicto al interior del Perú (McEvoy, 2011: 345). Esta situación fue paulatinamente dejada sin efecto, en la medida que el sistema paralelo fracasó en su intento de funcionar como un sistema alternativo óptimo para la solución de los conflictos en un contexto de ocupación (Aguilar, 2012: 177). El reconocimiento del fracaso se debió a que los diversos actores implementaron diferentes estrategias en la judicialización de sus conflictos. Frente al proyecto político de justicia criminal que buscaba establecer un orden tomando en cuenta a los diferentes grupos, emergió una cultura judicial con una diversidad de tácticas expresada en una variedad de discursos, actitudes y representaciones en sus prácticas de justicia debido al dualismo judicial imperante; como consecuencia de su fracaso los constructores de la institucionalidad judicial terminaron por decidir la imposición de la justicia chilena, la cual finalmente optó por defender principalmente los intereses particulares que para los ocupantes revestían importancia (extranjeros y chilenos), buscando mantener la eficiencia en los controles sociales (Brangier, 2011: 2). 


\section{Deconstruyendo la justicia criminal: una mirada desde los actores}

La renovación temática que vienen atravesando los estudios sobre la Guerra del Pacífico, se debe a una serie de factores como el uso de nuevos tipos de fuentes documentales, provenientes de archivos provinciales y privados, las diversas fuentes judiciales: civiles, criminales, policiales, carcelarias, las publicaciones como periódicos y revistas, los documentos en archivos municipales y un número creciente de fuentes no escritas como fotografía, música, teatro, etc. (Aguirre, 2008). Otro factor es la renovación teórica y metodológica, "tal vez el más crucial haya sido el difícil tránsito del estudio de las estructuras materiales al de la cultura, la subjetividad y sus representaciones" (Sandoval, 2010: 8). La historia de la Guerra del Pacífico se ha enriquecido al pasar de una preocupación en las "fuerzas históricas "objetivas" al énfasis en la subjetividad, la creatividad y la agencia; de las condiciones materiales de existencia a las percepciones, los símbolos y sus significados; y de lo que fue caracterizado como infraestructura a la denominada superestructura" (Sandoval, 2010: 8). Al pasar de los aspectos estrictamente militares y económicos a los sociales y culturales, siendo "abordada desde los protagonistas, entregaría una nueva visión, más cercana y próxima, permitiendo alternar las visiones de vencedores y vencidos" (Rivera, 2015: 274).

Uno de los temas de renovación más interesantes son los que abarcan la vida cotidiana (Huaman, 2009) y la interacción entre las poblaciones peruanas y chilenas (Valle, 2013). Ambas temáticas de investigación han permitido ir superando la imagen maniquea que ha predominado sobre la ocupación chilena de la capital, la cual sostiene que la población limeña rechazó hostilmente al ejército invasor; por el contrario lo que buscan explorar estos estudios es investigar sobre el nivel de contacto que necesariamente tuvo que darse entre ambas poblaciones, la que se produjo incluso antes de la guerra de 1879. Lo que emerge es una imagen de complejidad en las relaciones de convivencia entre peruanos y chilenos. Una línea de investigación que busca aportar en esta dirección, son los estudios sobre cotidianidad judicial, los procesos de formación de la justicia y de su administración a través de sus agentes judiciales:

"Historizar la justicia en el contexto del quehacer cotidiano invita a considerar una gama de posibilidades exploratorias. La justicia examinada desde los afanes y circunstancias del día a día se enfrenta con los usos de la ley, con la direccionalidad de la justicia, con los tribunales, con los agentes de justicia, con sus usuarios, con las pruebas y testimonios, con la prensa y la academia, con experiencias individuales y colectivas. La justicia en el cotidiano se enfrenta con prácticas, sentires e intenciones, con historias y relatos, con expectación y silencio" (Correa, 2014: 6). 
Para ello se hará un estudio cualitativo tomando en cuenta los discursos y el comportamiento de los litigantes ante los tribunales del crimen. Observaremos cómo se resolvieron los conflictos interpersonales y se sancionaron las conductas antijurídicas. Si algo podemos observar de los procesos criminales estudiados son las siguientes características: (1) predominio del juez, quien tiene a su cargo el sumario y el plenario; (2) prisión preventiva mayormente obligatoria; (3) ostensible falta de derechos de los imputados; (4) prueba tasada como criterio de valoración, (5) predominancia de la escrituralidad, siendo esencialmente burocrática. De los 411 expedientes ubicados en el Archivo General de la Nación de Lima (AGN) con respecto a los años de ocupación de la capital, entre 1880-1881 se han encontrado 34 expedientes, en 1882 son 113 expedientes y en 1883 son 264 expedientes, siendo el año que tiene la mayor cantidad de procesos judiciales.

Tabla 1 Causas Criminales, 1880-1883

\begin{tabular}{|c|c|c|}
\hline Legajo $\mathbf{N}^{\mathbf{0}}$ & Legajo $^{\mathbf{0}}$ & Número de expedientes \\
\hline 376 & $1880-1881$ & 34 \\
\hline 377 & 1882 & 26 \\
\hline 378 & 1882 & 48 \\
\hline 379 & 1882 & 18 \\
\hline 380 & 1882 & 21 \\
\hline 381 & 1883 & 33 \\
\hline 382 & 1883 & 49 \\
\hline 383 & 1883 & 45 \\
\hline 384 & 1883 & 26 \\
\hline 385 & 1883 & 48 \\
\hline 386 & 1883 & 15 \\
\hline 387 & 1883 & 18 \\
\hline 388 & 1883 & 13 \\
\hline 389 & 1883 & 34 \\
\hline
\end{tabular}

Fuente: Elaboración propia

El cuadro elaborado a partir del número de expedientes encontrados en el AGN, nos permite proponer algunas aproximaciones sobre el carácter de las relaciones establecidas entre peruanos y chilenos dentro de la esfera de la resolución de conflictos como fueron los juzgados criminales y sus agentes judiciales. El año de 1881 tendría la menor cantidad de expedientes presentados, en la medida que debe ser visto como un año de transición, donde las autoridades chilenas de ocupación esperaban que los funcionarios judiciales peruanos regularizasen los servicios de administración de justicia, los cuales se encontraban en su periodo vacacional; debido a ello en febrero establecieron los Tribunales Militares que implementarían la ley marcial, en noviembre cuando observaron que los juzgados peruanos no 
retomarían las labores judiciales se estableció el sistema dual de juzgados civiles y criminales. En 1882 la administración de justicia se estaba estabilizando gradualmente, a pesar de ello debido al fracaso paulatino del sistema paralelo por la acción de los litigantes en las instancias de resolución de conflictos, donde fueron apelando constantemente a la ley peruana, es que se fue restringiendo su aplicación ante los tribunales de ocupación, trayendo como consecuencia que se fuera apelando cada vez más a la legislación chilena. Finalmente para 1883 el sistema buscó ser estabilizado nuevamente, aunque terminó totalmente desbordado, en la medida que si bien se impuso la legislación chilena, la apelación a la normativa peruana, o ambas en paralelo, fue cada vez mayor y de forma indistinta, revelando una cultura jurídica compleja, cruzada por prácticas envueltas en una diversa elaboración de discursos, actitudes y sensibilidades, vínculos de poder y relaciones sociales de la vida cotidiana.

A partir del estudio de las causas criminales buscaremos aproximarnos a la forma como establecieron sus relaciones de convivencia peruanos y chilenos con la administración de justicia y sus agentes judiciales, en la medida que los archivos judiciales al ser una inagotable fuente de discursos, expresan la forma como se construye la cotidianidad de la vida de quienes se encuentran involucrados en procesos por diversos delitos (Albornoz, 2005: 1-2). Como hemos mencionado líneas arriba la justicia chilena fue bastante flexible en la medida que la ocupación de la capital fue "adquiriendo forma y sentido a través de un complejo proceso de error-acierto" (McEvoy, 2011: 337). Hubo todo un proceso de aprendizaje por parte de los invasores bastante complejo, que expresaba las limitaciones de los vencedores, y una variedad de acciones por los vencidos (McEvoy, 2011: 337). Presentamos a través de un cuadro los tipos de casos que hemos encontrado en los casi 60 expedientes criminales revisados por nosotros. 
Tabla 2 Tipología de casos

\begin{tabular}{|c|c|}
\hline Tipo de Casos & Cantidad \\
\hline Abuso de autoridad & 1 \\
\hline Abuso de confianza & 3 \\
\hline Acusación de ser chileno & 1 \\
\hline Apelación de Hecho & 1 \\
\hline Apelación de libertad bajo fianza & 1 \\
\hline Cobro de costas & 1 \\
\hline Conato reiterado de homicidio & 11 \\
\hline Estafa & 4 \\
\hline Homicidio & 2 \\
\hline Hurto & 10 \\
\hline Injurias & 3 \\
\hline Lesiones & 1 \\
\hline Prevaricato & 11 \\
\hline Robo & 3 \\
\hline Salteo & 1 \\
\hline Sodomía & 1 \\
\hline Violación & 1 \\
\hline Sustracción & 57 \\
\hline Total & \\
\hline & \\
\hline & \\
\hline
\end{tabular}

Fuente: Elaboración propia

Haciendo un listado de la mayor cantidad de casos presentados ante las instancias judiciales destacan por tipo y número los de robo (11), estafa (11), injuria o calumnia (10), homicidios (4), lesiones o heridas (3), abuso de confianza (3), salteo (3). Además, encontramos también otros casos en cantidad menor: prevaricato (1), sustracción (1), violación (1). Siendo los casos de hurto o robo los más recurrentes, entre ellos encontramos variedad de actores sociales involucrados, vinculados además a grupos étnicos específicos. Evidencia de ello son los casos de negros, indígenas, chilenos, extranjeros (asiáticos en su mayoría y algunos italianos) entre otros. Este es el caso de Gregorio Sánchez, cuyo juicio iniciado en 1880 por delito de robo, en diciembre cuando Lima estaba en emergencia y antes del periodo de vacaciones del Poder Judicial, el juez Manuel Aurelio Bonilla sentenció: "Hago constar por la presente que este juicio ha tenido paralización por la circunstancia actual de guerra doy fe".${ }^{6}$ Con la ocupación de la capital la justicia chilena lo puso

6 Archivo General de la Nación, Repositorio del Poder Judicial, (en adelante AGN, RPJ) Causas Criminales, 1880, Leg. 376, f. $11 \mathrm{v}$. 
en libertad el 4 de junio de 1881, 7 tras el retiro de las fuerzas invasoras el 10 de agosto de 1885 la justicia peruana resuelve:

"Con lo expuesto por el agente fiscal, y teniendo en consideración que el reo Gregorio Sánchez fue puesto en libertad de orden de las autoridades de la ocupación, que en virtud de lo articulado en el artículo trece del Tratado de Paz con Chile, son válidos los actos administrativos y judiciales practicados por dichas autoridades. Por estos fundamentos, córtese el seguimiento del presente juicio y archívense los de la materia. Ramón Ronco"8.

Como puede observarse no solamente la justicia chilena aceptó pragmáticamente la vigencia de la justicia peruana, sino también la justicia peruana cuando retomó sus funciones jurisdiccionales ante el retiro de los invasores, aceptó lo actuado por los jueces chilenos. Esto se debe como indicamos anteriormente a la similitud con respecto a ambos códigos penales, los cuales por ejemplo parten de la misma definición del delito visto como "toda acción u omisión voluntaria penada por la ley".

En el juicio criminal seguido contra Pablo y Mariano, y Agustín y Manuela Rivas por robo, iniciado el 15 de diciembre de 1880, con la ocupación de la capital el 8 de marzo de 1881, en plena vigencia de la ley marcial son puestos en libertad Pablo y Mariano por parte de la justicia chilena. Ante ello Agustín Rivas demanda:

"Hago presente a Usted que los demás delincuentes han sido puestos en libertad por orden de la autoridad chilena como consta de la razón del actuario y tratándose o habiéndose expedido orden de libertad por mí mismo también, no la acepté, porque no la creí legal. Ruego pues a usted que tome en consideración lo expuesto para que la justicia ordene mi libertad". ${ }^{9}$

El aprendizaje no solo fue de parte de los jueces chilenos, también lo fue de los imputados o inculpados, quienes debieron diseñar nuevas estrategias de litigio ante la emergencia de poderes judiciales extraterritoriales; en el caso de Agustín Rivas fue la necesidad de pensar sobre lo legal y lo ilegal de la situación generada por los nuevos aparatos jurisdiccionales, así como lo justo y lo injusto de sus fallos (Brangier, 2013), para ello tuvieron que posicionarse en las instancias judiciales, distinguiendo los efectos que tiene en la persona la condición de encierro y libertad. 
Debido al fracaso del sistema dual, en un segundo momento se busca imponer la justicia chilena, prueba de su liberalismo pragmático y autoritario que "encuentra su expresión más acabada en la ocupación de Lima" (McEvoy, 2011: 354). En la denuncia que hace Francisco Netto contra Angela Miguelini por injurias contra su esposa "tratándola de meretriz y corrompida y del mismo modo a su familia", la demandada niega la acusación y se contraquerella por injurias de hecho, el juez Evaristo Sanz resuelve el 26 de noviembre de 1881:

Considerando: $1^{\circ}$ que el demandante no ha producido ninguna prueba para justificar su querella. $2^{\circ}$, que la demandada ha justificado plenamente las injurias en su contra, lo cual está de manifiesto que la señora de Netto infirió crímenes leves a Angela Miguelini y que también le ha inferido injurias de palabras. De conformidad a lo dispuesto por el artículo 494, inciso 5to y 496, inciso 11 vo del código penal, condeno a la señora Netto a sufrir cuarenta días de prisión conmutables en 20 pesos de multa y las costas. ${ }^{10}$

Como señala María Eugenia Albornoz (2005: 3), la injuria en su dimensión de pleito judicial permite introducirnos a diferentes esferas como la vida cotidiana, en la medida que permite el "doble juego de roles: la persona querellada puede contra querellarse y entonces se tiene la simultaneidad de lugares en el escenario judicial: acusado se vuelve acusador y viceversa, con el consecuente manejo de argumentos para desplazar la culpa desde sí mismo hacia la otra "parte" envuelta en el proceso". Todo esto hace compleja la convivencia entre las personas, las cuales en los casos de injurias se conocían entrando en conflictos verbales atentando contra la honra y el honor.

A partir de aquí es que los litigantes comienzan a tener interés por conocer mejor la legislación chilena. En otro juicio seguido por injurias, el demandante Manuel Rodríguez pide "aplicar al delincuente el máximo de la pena que señala a esta clase de injurias el artículo 418 del Código Penal de la República de Chile". ${ }^{11}$ Uno de los testigos califica el hecho de "muy grave, pues le llamo ladrón públicamente", otro testigo presentado por Rodríguez lo desmiente. "El testigo, don Andrés Lauder ha dicho falso testimonio en su declaración obligada y como su juicio me perjudica, pongo a disposición de usted la siguiente información". ${ }^{12}$ La complejidad de estas violencias interpersonales que hacen que el insulto sea convertido en injuria querella-

10 AGN, RPJ, Causas Criminales, 1882, Leg. 377, f. 5v.

11 AGN, RPJ, Causas Criminales, 1882, Leg. 377, f. 2. El art. 418 señala que las injurias graves hechas por escrito i con publicidad, serán castigadas con las penas de reclusión menor en sus grados mínimo a medio i multa de quinientos a mil pesos. No concurriendo aquellas circunstancias, las penas serán reclusión menor en su grado mínimo i multa de ciento a quinientos pesos.

12 AGN, RPJ, Causas Criminales, 1882, Leg. 377, f.11. 
ble, llevado así ante los jueces debe ser probado mediante la palabra de los testigos (Albornoz, 2005: 3), lo cual hace que la apelación a la ley sea de lo más abierta buscando el mayor beneficio posible.

El mejor conocimiento de la justicia chilena permite cuestionar sus limitaciones por parte de los litigantes. Sobre un caso de reapertura de juicio por entrega de relojes, el denunciado, un ciudadano de origen italiano señala:

"En efecto, sea que se estudie el asunto bajo el aspecto de la legislación Chilena o Peruana, es un hecho indisentible, que no es permitido a ningún litigante después de entablado un juicio y al notificado al contrario, y sin desistirse de esa demanda, entablar la misma demanda, porque esto sería establecer una grave confusión y complicaciones diarios que harían imposible la administración de justicia. Y en la República de Chile Sr. Juez, que tan severa es en este ramo de su administración, no se acepta semejante procedimiento, lo cual constituye una garantía para el demandado, garantía que por tanto aquí como allá, tienen derecho de invocar los ciudadanos extranjeros". ${ }^{13}$

Pero las limitaciones no provienen solamente de lo normado por el código penal chileno, sino también por lo actuado por Patricio Lynch, quien en el decreto emitido el 6 de noviembre de 1881 concluye "afirmando que no es deber del ocupante impedir que los peruanos se hagan a sí mismos todo el mal que quieran hacerse pero que, dado que la ocupación se venía alargando más tiempo del que se pensó en un inicio, correspondía establecer medidas provisorias que atenúen el problema" (Aguilar, 2012: 146). A esto responde el demandado en el caso anteriormente mencionado:

"El Reglamento vigente dictado por el Jefe Político General Linch, de fecha 6 de noviembre de 1881, que es la norma de los procedimientos de Ud., no se ocupa de las causas radicadas ante los tribunales peruanos, sino de las demandas nuevas. Así lo expresa claramente el artículo $3^{\circ}$ del párrafo $1^{\circ}$ de dicho reglamento, pero aunque no lo dijese, sería legítima mi oposición porque el indicado reglamento solo ha tenido por objeto remediar una necesidad de momento y de casos urgente, necesidad y urgencia que no existe tratándose del pleito entre el infrascrito (el demandado) y el Sr. Rotalde (demandante)" ${ }^{14}$

Los cuestionamientos a la justicia chilena permiten apelar a la justicia peruana como se observa en el juicio por lesiones graves denunciado por Carmen Preciado; la afectada presenta el siguiente argumento para que se

AGN, RPJ, Causas Criminales, 1882, Leg. 377, f. $10 \mathrm{v}$.

AGN, RPJ, Causas Criminales, 1882, Leg. 377, f. 4. 
deje sin efecto el pedido de libertad bajo fianza de los implicados Bartolomé Venegas, Rosario Castillo de Venegas y Zoilo Padilla, luego que su caso pasó del juzgado local de Chancay al Tribunal Militar:

"Sr. Presidente del Tribunal (...) no creo demás recordar a ud que el Código Penal Peruano niega la soltura en fiador cuando el delito materia de la querella merece la pena de cárcel y como según lo dispuesto en el artículo 249 del citado código, es explicable dicha pena en $4^{\circ}$ grado cuando de las lesiones resulta notable deformidad"..$^{15}$

Incluso los litigantes podían usar ambos códigos en forma paralela, como se produjo en el juicio seguido por Manuel Castro contra Toribio Mora y otros que robaron en su casa, cuando señala que:

"la responsabilidad recae tanto en lo criminal como en lo civil contra los autores, cómplices y encubridores conforme a los artículos 11 y 18 del Código Penal Peruano que debe aplicarse al fallo (...) que pido contra José Montalvan en cuyo poder se ha encontrado el robo, la indemnización del valor de las especies que me faltan (...) y considéresele a Montalvan como autor o encubridor conforme a las disposiciones del Codigo Penal Chileno referente a robos y hurtos, mandadas a poner en vigencia por decreto del cuartel general antes citado". ${ }^{16}$

Una medida para superar el fracaso del sistema paralelo fue el decreto dado por Patricio Lynch el 11 de julio de 1882, el cual pasa "por alto toda referencia al derecho peruano y señala de forma clara que el derecho que se debía aplicar para la sanción de estas conductas seguía siendo la ley marcial dispuesta por el ejército invasor" (Aguilar, 2012: 159). En el juicio seguido contra José Villegas por el homicidio del Cabo chileno Telésforo Beltrán, el abogado defensor, señala que no se puede pedir la pena de muerte para su defendido, cuando se dio el suceso no estaba vigente el decreto del 11 de julio que estipulaba las diferencias penales entre chilenos y peruanos, "cuando se cometió el delito, no había distinción ante la ley entre chilenos y peruanos, ni entre paisanos y soldados y el decreto que a este punto refiere es de fecha posterior". ${ }^{17}$ Esta última cita documental expresa las dificultades por las que tuvo que atravesar la administración chilena, en especial la de Patricio Lynch, por buscar implementar un adecuado sistema de administración judicial en un contexto de ocupación, el cual terminó fracasando. 


\section{Conclusiones}

El proyecto político de justicia criminal implementado por Chile durante la ocupación de Lima, se caracterizó por su pragmatismo, debido a las dificultades que tuvo que afrontar para una adecuada administración de una ciudad capital invadida como Lima. El Estado chileno terminó desdoblándose debiendo adaptarse a un escenario nuevo el cual tuvo que administrar, como fue el de la justicia; para ello los agentes judiciales invasores organizaron un sistema jurídico dual, empleando pragmáticamente tanto la legislación chilena como peruana, buscando superar los conflictos interpersonales con el objetivo de mantener el orden social, el cual terminó fracasando por la diversidad de tácticas jurídicas empleadas, expresadas a través de una variedad de discursos, actitudes y representaciones. El observar la justicia como un problema de Estado y a los diferentes actores sociales a través de las prácticas de los litigantes, nos permitió comprender la imagen de justicia que tuvieron tanto los administradores judiciales como los diversos grupos que constituyeron una especie de sociedades paralelas, en una coyuntura de inevitable convivencia social. Así el pragmatismo jurídico de los agentes judiciales se mezcló con una diversa y compleja movilidad jurídico-social por parte de peruanos, chilenos y colonias extranjeras. El fracaso de los constructores de la institucionalidad judicial expresada en las dificultades para lograr una satisfactoria contención social, terminaron por decidir imponer la justicia chilena, defendiendo principalmente los intereses particulares que para los invasores tuvieron importancia, como fueron los extranjeros y chilenos.

\section{Referencias bibliográficas}

\section{Fuentes Primarias}

Código Penal de la República de Chile (1874). Santiago de Chile: Imprenta de la República.

\section{Fuentes Secundarias}

\section{a. Artículos}

Brangier, V. M. (2011). "Justicia Criminal en Chile, 1842-1906. ¿Debido proceso o contención social?", en Revista Sociedad \& Equidad, № 1, p. 1-26.

Brangier, V. M. (2013). "Sentidos de "lo justo e injusto". Judicialización de conflictos interpersonales. Chile central, 1824-1875", en Revista Historia y Justicia, No1, p. 1-33. 
De Ramón, A. (1989). "La justicia chilena entre 1875 y 1924", en Cuadernos de Análisis Jurídico, № 12, p. 1-59.

Fernández Labbé, M. (2000). "La explicación y sus fantasmas. Representaciones del delito y de la eximición de responsabilidad penal en el Chile del siglo XIX", en Revista de Historia Social y de las Mentalidades, № 4, p. 105-130.

Huamán Guardia, R. (2013). "La ciudad silenciosa. Algunos aspectos de la vida en Lima durante la ocupación chilena 1881-1883", en Nueva Corónica, № 2, p. 395-404.

Iñesta Pastor, E. (2005). "La reforma penal del Perú independiente: el código penal de 1863", en Torres Aguilar, M. (Coord). Actas del XV Congreso del Instituto Internacional de Historia del Derecho Indiano, p. 1073-1098.

Iñesta Pastor, E. (2008). "Antecedentes histórico-jurídicos del código penal chileno de 1874", en De La Puente Brunke, J. y Guevara Gil, J. (Edits). Actas del XIV Congreso del Instituto Internacional de Historia del Derecho Indiano, p. 203-242.

Rivera, P. (2015). "Lo que se escribe, lo que se enseña: guerra de 1879", en Cavieres, E. y Chaupis Torres, J. (Edits). La Guerra del Pacífico en perspectiva histórica. Reflexiones y proyecciones en pasado y en presente. Chile: Universidad de Tarapacá, p. 273-286.

Rivera Serna, R. (1984). "La ocupación chilena de Lima. Aspectos políticos-administrativos", en: Rivera Serna, R. et al. La Guerra del Pacífico. Lima: Universidad Nacional Mayor de San Marcos.

Zúñiga Urbina, F. (2010). "Constitución conservadora chilena de 1833 y la visión crítica de Alberdi", en UNED. Revista de Derecho Político, № 78, p. 377-397.

\section{b. Libros}

Abanto, J. C. (2012). Encarando el desastre. El conflicto hegemónico entre la burguesía limeña y los terratenientes serranos del norte en la Guerra con Chile 1881-1884. Lima: Universidad Nacional Mayor de San Marcos.

Aguilar Rojas, G. (2012). La administración de justicia en Lima durante la ocupación chilena (1881-1883). Lima: Pontificia Universidad Católica del Perú, tesis de licenciatura en Historia.

Aguirre, C. (2008). Denle duro que no siente. Poder y transgresión en el Perú republicano. Lima: AFINED.

Atanasio Fuentes, M. (1881). Ramillete o repertorio de los más piramidales documentos oficiales del gobierno dictatorio con una parodia al lado en vil verso redactada por Fray Benito Encalada Montestruque y Maldonado. Lima: Imprenta del Universo de Carlos Prince. 
Basadre, J. (2005). Historia de la República del Perú (1822-1933). Lima: Empresa Editora El Comercio, t. IX.

Corte Suprema de Justicia de la República (1911). Anales Judiciales de la Corte Suprema de Justicia. 1880-1887. Lima: Imprenta La Industria, t. IV.

Chaupis Torres, J. y Rosario, E. (Comps.) (2007). La Guerra del Pacífico. Aportes para repensar su historia. Lima: Editorial Línea Andina-Universidad Nacional Mayor de San Marcos, v. I.

Correa, M. J. (Coorda). (2014). Justicia y vida cotidiana en Valparaíso. Siglos XVIIXX. Chile: Universidad Andrés Bello-Acto Editores.

Garaycott, N. (2012). Política criminal en la constitución política del Perú. Lima: Editorial San Marcos.

Guerra Martiniere, M. (1991). La ocupación de Lima (1881-1883). El gobierno de García Calderón. Lima: Pontificia Universidad Católica del Perú.

Mc Evoy, C. (1997). La utopía Republicana. Ideales y realidades de la formación política de la cultura peruana. Lima. Pontificia Universidad Católica del Perú.

Mc Evoy, C. (2011). Guerreros civilizadores. Política, sociedad y cultura en Chile durante la Guerra del Pacífico. Lima: Centro de Estudios Bicentenarios.

Ramos Núñez, C. (2008). Historia de la Corte Suprema de Justicia del Perú. Lima: Fondo Editorial del Poder Judicial.

Rosario, E. (2014). Parlamentos en conflicto. El congreso de la república y la Guerra del Pacífico (1879-1881). Lima: Universidad Nacional Mayor de San Marcos.

Sánchez Velarde, P. (2004). Manual de derecho procesal penal. Lima: IDEMSA.

Sandoval, P. (Comp). (2008). Repensando la subalternidad. Miradas críticas desde/sobre América Latina. Lima: Instituto de Estudios Peruanos-Envión Editores.

\section{c) Otros}

Albornoz Vásquez, M. E. (2005). "La Injuria de Palabra en Santiago de Chile, 16721822", en Nuevo Mundo, Mundos Nuevos, disponible en http://nuevomundo. revues.org/240, visitado el 21 diciembre de 2015. 